\title{
High Temperature Electrolysis of Ti and Its Alloys with a DC-ESR Unit
}

\author{
Toshihide Takenaka ${ }^{a}$, Hidetaka Matsuo ${ }^{b}$, Mitsuru Sugawara ${ }^{c}$ \\ and Masahiro Kawakami ${ }^{d}$ \\ Toyohashi University of Technology, Tempaku-cho, Toyohashi 441-8580, Japan \\ atakenaka@pse.tut.ac.jp, ${ }^{b}$ matsuo@tf.pse.tut.ac.jp, 'csugawara@tf.pse.tut.ac.jp, \\ dkawakami@pse.tut.ac.jp
}

Keywords: Ti, Ti-Al, Ti-Fe, electrolysis, ESR, molten salt

\begin{abstract}
Direct electrolysis of Ti and its alloys has been attempted by the process using a DC-ESR unit. The concept of the process is explained in detail, and the expected key issues are commented. Liquid Ti metal was obtained in $\mathrm{a} \mathrm{CaF}_{2}-\mathrm{CaO}-\mathrm{TiO}_{2}$ bath, and electrolysis by using a new type of the electrolytic cell was also tried. Ti-Al alloy was successfully deposited in a $\mathrm{CaF}_{2}-\mathrm{CaO}-\mathrm{TiO}_{2}-\mathrm{Al}_{2} \mathrm{O}_{3}$ bath, whereas Ti-Si alloy was not obtained in a $\mathrm{CaF}_{2}-\mathrm{CaO}-\mathrm{TiO}_{2}-\mathrm{SiO}_{2}$ bath yet. Ti-Fe alloy was extracted in $\mathrm{CaF}_{2}-\mathrm{CaO}-\mathrm{TiO}_{2}-\mathrm{FeO}$ bath of a particular composition. A common correlation between the cathodic current efficiency and the average consumed electric power seen in the Ti, Ti-Al and Ti-Fe electrolysis suggested the importance of sufficient temperature in the process. The bath composition also affected the temperature through the change in the electric conductivity of the bath.
\end{abstract}

\section{Introduction}

Application of Ti and its alloys is still limited though they have many superior characteristics, such as high specific strength and high corrosion resistivity. Because the natural resource of Ti is plentiful, there are a big potential for applying them widely. One of the main reasons of the restriction is the high cost in its smelting.

Ti metal is produced by Kroll process now, and this process gives Ti metal of very high grade. However, Kroll process is a well-developed system including some batch steps, so that it is difficult to improve its efficiency remarkably. Therefore, a breakthrough in Ti production has been required to reduce the production cost, and many well-designed processes have been proposed [1-3].

It is desirable to obtain liquid metal in its smelting process from the view of production efficiency, and huge amounts of $\mathrm{Fe}$ (steel) and $\mathrm{Al}$ metal in liquid are produced industrially. Some trials of liquid Ti metal production were reported [4], and our group also proposed a process by using a DC-ESR unit. Electrolysis in our process was performed at very high temperature in a molten $\mathrm{CaF}_{2}-\mathrm{CaO}$ bath containing $\mathrm{TiO}_{2}$, and Ti metal in liquid was obtained under suitable conditions [5-6]. Moreover, $\mathrm{Ti}-\mathrm{Al}$ alloy was deposited in a molten $\mathrm{CaF}_{2}-\mathrm{CaO}-\mathrm{TiO}_{2}-\mathrm{Al}_{2} \mathrm{O}_{3}$ bath [7-9].

In this paper, the concept of our process is explained in detail, and the key issues we expected are commented. The metal deposits actually obtained by the process are described, and the conditions for efficient electrolysis are discussed. Based on these results and consideration, the prospect of the process is mentioned.

\section{Process Concept}

Our proposing process is performed by using a DC-ESR (direct current electro-slag remelting) unit.

An ordinary ESR process is industrially applied for purification of steel, where high AC or DC current flows between a consumable steel rod suspended in molten slag and the bottom of a water-cooled vessel as shown in Fig.1(a). The consumable steel rod is remelted by Joule's heat in the bath, and the melted steel droplets form a metal pool on the bottom. In our process as shown in Fig.1(b), DC current is applied in a similar setup, where a graphite rod substituted for a consumable 


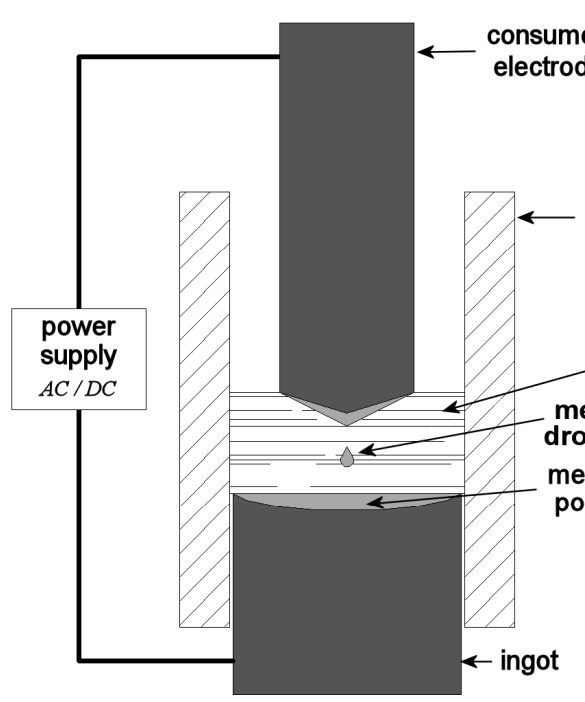

a) ESR setup

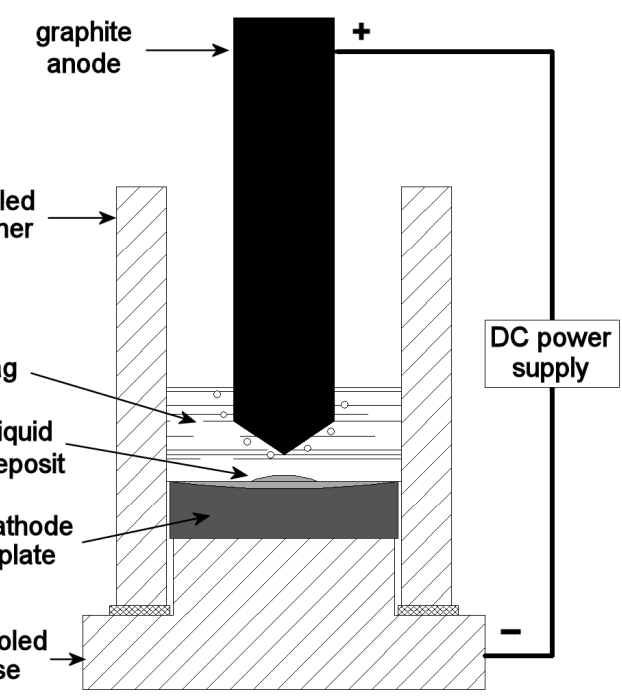

b) setup for Ti electrolysis

Fig.1 Setups of ESR operation and Ti electrolysis by using DC-ESR unit.

steel rod and the bottom of the vessel act as anode and cathode, respectively. In a bath containing $\mathrm{Ti}$ ions, electrodeposition of liquid Ti metal can be expected at the cathode if sufficient Joule's heat is generated. The presumed reactions at the cathode and the graphite anode in a bath containing Ti(IV) ions and oxide ions are roughly described as follows;

$<$ cahode $>\quad T i(\mathrm{IV})+4 e^{-}=T i$

$<$ anode $>\mathrm{n} O^{2-}+C=C O_{n}+2 \mathrm{n} e^{-}$

$$
\mathrm{n}=1 \text { or } 2
$$

Reaction(1) is essential for the process doubtlessly. Because it is well-known that electrodeposition of metal in molten salt is strongly affected by electrolysis conditions, the necessary conditions for Reaction(1) must be clarified in our process. The composition of electrolytic bath is supposed important, and the control of the cathode potential should be necessary; the cathode potential must be less-noble enough for Reaction(1), because insufficient cathode potential can cause the formation of lower-valent $\mathrm{Ti}$ ions, such as $\mathrm{Ti}$ (II) or Ti(III). The lower-valent ions usually bring on the so-called shuttle reaction as follows, and Ti metal is hardly obtaind at the cathode;

$$
\begin{array}{lll}
<\text { cathode }> & T i(\mathrm{IV})+\mathrm{m} e^{-}=T i(\mathrm{II} \text { or } \mathrm{III}) & \mathrm{m}=1 \text { or } 2 \\
<\text { anode }> & T i(\mathrm{II} \text { or } \mathrm{III})=T i(\mathrm{IV})+\mathrm{m} e^{-} &
\end{array}
$$

However, too negative cathode potential may cause the decomposition of the bath, namely Ca metal deposition in $\mathrm{a} \mathrm{CaF}_{2}-\mathrm{CaO}$ bath. Since the cathode potential itself is hardly measured in our system, the proper control of the cell voltage has been attempted.

Sufficient generation of Joule's heat should be also key in the process, because direct electrolysis of Ti metal in liquid is a main target. Moreover, electrodeposition of solid Ti metal may result in the obstruction of further Ti deposition; solid Ti metal can be removed by the strong convection in the bath with high current flow at high temperature. The potential of Ti metal removed in the bath is not controlled, so that it should react with Ti ions in the bath and generate the lower-valent Ti ions.

Small distance between the cathode and the anode causes arc discharge, and current is not used to the electrolysis. The larger electrode distance is also preferable from the view of the impurity content in the deposit; although $\mathrm{CO}_{3}{ }^{2-}$ should be unstable in this system, $\mathrm{CO}$ bubbles formed at the anode can reach to the cathode. $\mathrm{CO}$ should react with $\mathrm{Ti}$ metal deposit on the cathode, and result in not only the contamination of $\mathrm{C}$ and $\mathrm{O}$ in the deposit and also the deterioration of the cathodic current efficiency. 
There are many subjects to be investigated and solved in our proposing process, but superior advantages can be expected; the process can significantly simplify Ti smelting in comparison to Kroll

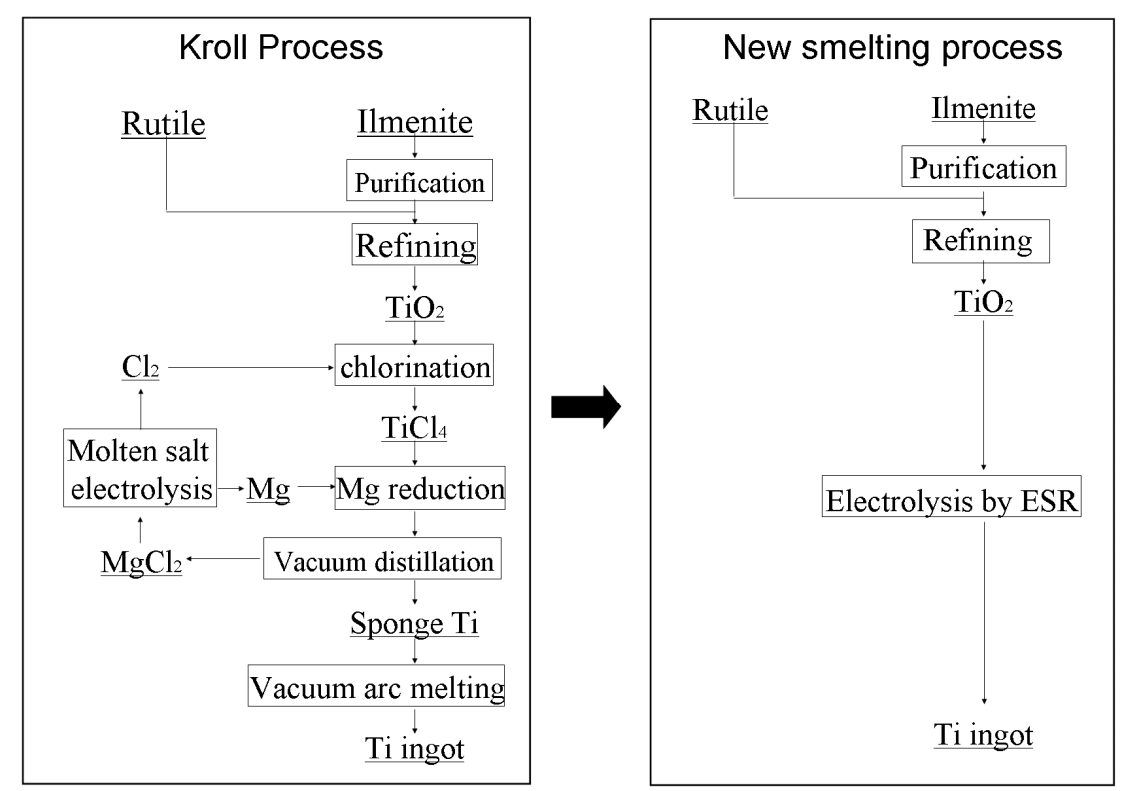

Fig.2 Schematic flows of Kroll process and our proposing process. [7]

process as shown in Fig.2 [7]. High electric power is required in our process, but it should be compensated by the absence of the vacuum distillation and vacuum arc remelting processes. There is a possibility of establishing a continuous process in our system, and the production efficiency should be remarkably improved in that case. The simpleness of the process also means a smaller labor and a fewer equipments. Furthermore, operation on demand may be possible because the proposed process can start and stop easily.

\section{Results and Discussion}

Ti electrolysis. Electrolysis was carried out in a $\mathrm{CaF}_{2}-\mathrm{CaO}-\mathrm{TiO}_{2}$ bath with a $\mathrm{DC}$ power supply (current-controlled, max. power: $100 \mathrm{~V}, 2 \mathrm{kA}$ ) in a water-cooled $\mathrm{Cu}$ vessel (I.D. $110 \mathrm{~mm}$ ), and $\mathrm{Ti}$ deposition was certified as possible by the proposed process [5-6].

The consumed electric power was altered with the composition of the slag bath even when the conditions except for the bath composition were fixed (about $1.2 \mathrm{kA}$, electrode distance: about $3 \mathrm{~cm}$ ). The cathodic current efficiency also depended on the composition, and seemed to relate to the consumed electric power as shown in Fig.3 [6]. These results suggested that the ionic state of $\mathrm{Ti}$ in the bath changed with the bath composition, and that the ionic state of Ti directly influenced the cathodic reaction of Ti, such as Reaction(1). The electric conductivity of the bath should be altered by the bath composition, so that the change in the bath composition caused the change in the bath temperature. Since sufficient temperature to form a metal pool on the cathode is necessary for efficient electrolysis mentioned before, the bath composition should have indirectly influenced the cathodic current efficiency. The cathodic current efficiency and the average consumed power became maximum

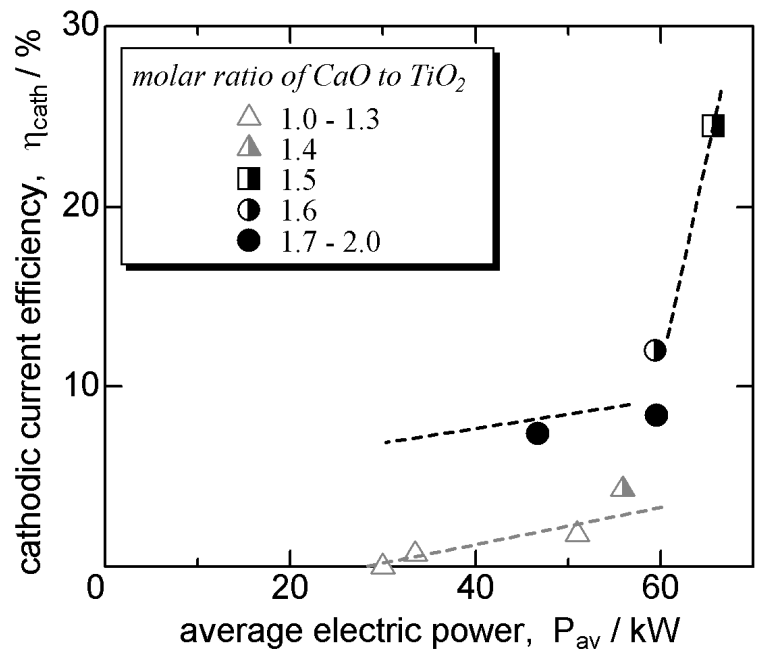

Fig.3 Relationship between average electric power and cathodic current efficiency in Ti electrolysis. [6] 
when the molar ratio of $\mathrm{CaO}$ with $\mathrm{TiO}_{2}$ in the bath was 1.5. The ions derived from $\mathrm{Ca}_{3} \mathrm{Ti}_{2} \mathrm{O}_{7}$, such as $\mathrm{Ti}_{2} \mathrm{O}_{7}{ }^{6-}$, seemed suitable for the proposed process. The maximum cathodic current efficiency was limited to about $25 \%$, but it can be bettered by optimizing the electrolysis conditions as described in the next section.

Ti metal obtained in the cell shown in Fig.1(b) contained a considerable amounts of $\mathrm{O}$ and $\mathrm{C}$ unfortunately, and the bigger distance seemed desirable as mentioned before. To keep an enough distance between the electrodes and to prevent $\mathrm{CO}$ bubbles from reaching the cathode, a cell consisting of two bodies with a connecting gutter as shown in Fig.4(a) was thought.

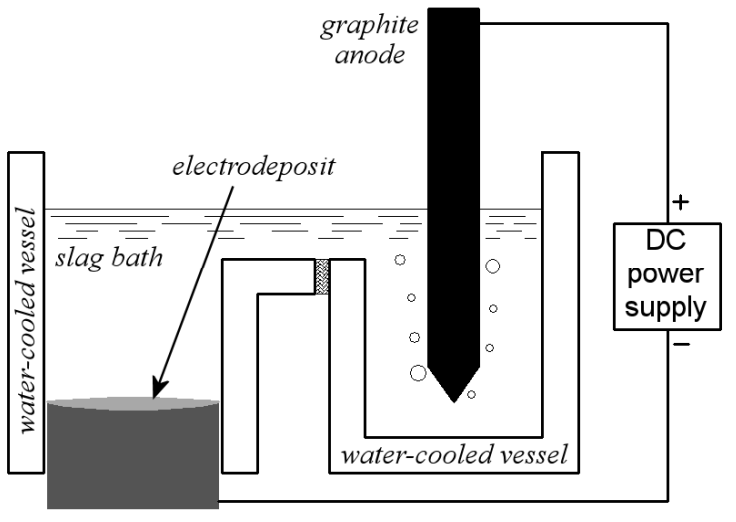

(a) image of 2-body cell

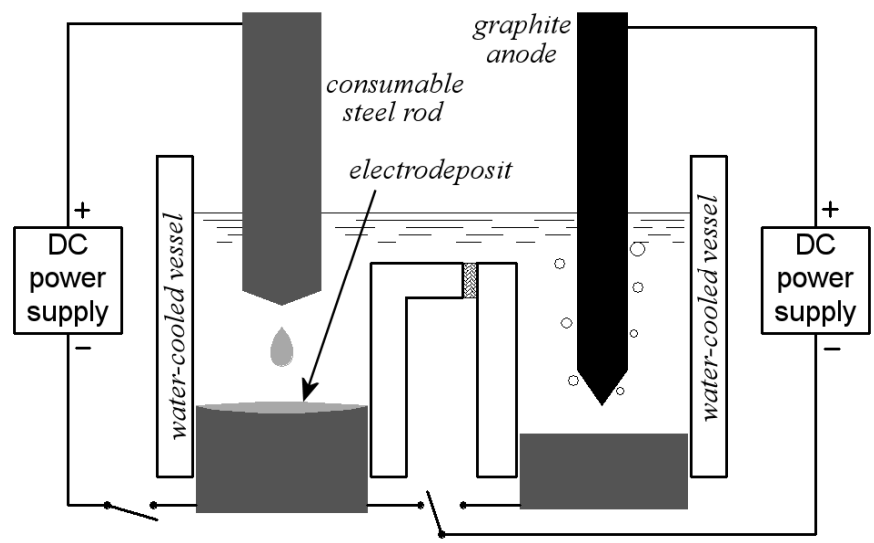

(b) actual setup consisting of 2 DC-ESR units

Fig.4 Illustration of 2-body cell and actual setup.

Since the so-called cold start operation was adopted in the actual experiments, electrolysis by using a cell consisting of two DC-ESR units with a connecting gutter as shown in Fig.4(b) was carried out; Ti electrolysis with a graphite anode and steel remelting with a steel consumed electrode started simultaneously, and their baths were joined through the gutter. After a sufficient amount of molten slag was formed on the gutter, the graphite anode and the bottom cathode of the other unit was directly connected.

It was found that current could flow between the graphite anode and the bottom cathode of the other unit as shown in Fig.5. However, the voltage reached the maximum of the power supply, so that the current became uncontrolled, namely insufficiently small. Consequently, the bath started solidifying after a few minutes. Electrolysis with a larger power supply is necessary.

Direct electrolysis of liquid Ti metal by our proposing process was shown possible, and the

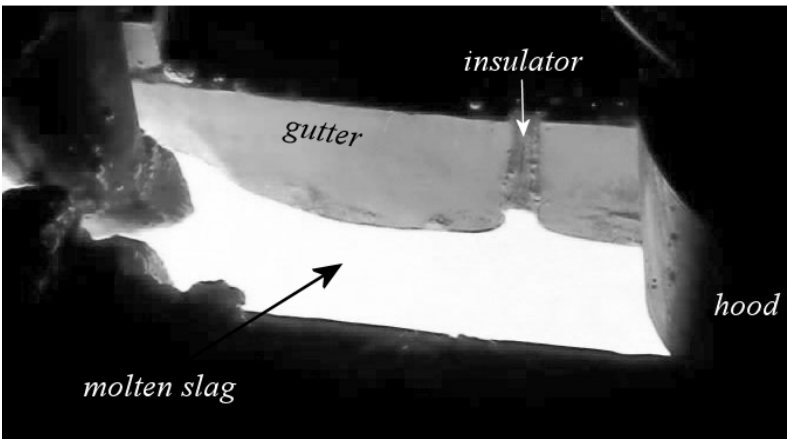

Fig.5 Appearance of 2-body cell in electrolysis. necessary conditions were getting unveiled. The improvement of the cathodic current efficiency and the impurity content were still necessary, and the measures to improve them have been considered and tried actually.

Ti alloy electrolysis. Direct production of Ti alloys has been attempted in some new Ti production processes [1-3], and was reported possible. In the process based on metallothermic reaction or electrochemical deoxidation, the composition of produced alloy could be controlled by that of the raw materials.

Direct production of $\mathrm{Ti}$ alloy by our process may be possible, but the kinds of $\mathrm{Ti}$ alloy and the obtained composition should be limited; the product is obtained by electrodeposition of metal in molten salt, and metals co-deposited with Ti should be limited. Even in the case that Ti alloy can be 
obtained, the composition should be controlled not only by the composition of the slag bath and also by other conditions, such as the cathode potential.

It was expected that there was a good possibility of direct production of Ti-Al alloy in our process, because the potentials of their electrodepositions were similar in many molten salt systems [10]. Actually, Ti-Al alloy was obtained by electrolysis in a $\mathrm{CaF}_{2}-\mathrm{CaO}-\mathrm{TiO}_{2}-$ $\mathrm{Al}_{2} \mathrm{O}_{3}$ bath, and the shapes of the deposit clearly indicated the alloy was deposited in liquid [7-8]. Fig. 6 shows the atomic ratio of $\mathrm{Ti}$ to $\mathrm{Al}$ in the obtained metal. The atomic ratio of $\mathrm{Ti}$ to $\mathrm{Al}$ was 2 3 and rarely depend on the bath composition. Fig.7 shows a typical XRD pattern of the deposit. Only $\mathrm{Ti}_{3} \mathrm{Al}$ was detected in the deposit, and this result is compatible with the atomic ratio of Ti to Al shown in Fig.6.

In the Ti-Al electrolysis, the cathodic current efficiency and the consumed electric power was also influenced by the composition of the slag bath. The consumed electric power tended to be larger than that in the Ti electrolysis mentioned before, and the cathodic current efficiency reached more than $50 \%$ under the suitable condition.

Liquid metal was electrodeposited by electrolysis in $\mathrm{CaF}_{2}-\mathrm{CaO}-\mathrm{TiO}_{2}-\mathrm{FeO}$ baths of various compositions, and the deposit did not contain $\mathrm{Ti}$ but mainly consist of $\mathrm{Fe}$ usually. However, Ti-Fe alloy where the weight ratio of $\mathrm{Ti}$ to $\mathrm{Fe}$ was about 1 was obtained in a particular bath composition with high cathodic current efficiency [9]. This result is significant, since Fe is considerably nobler than $\mathrm{Ti}$ electrochemically and co-deposition of $\mathrm{Ti}$ with $\mathrm{Fe}$ was supposed difficult even in our process. In the Ti-Fe electrolysis, the dependency of the cathodic current efficiency and the consumed electric power on the bath composition was similar to that in the Ti-Al electrolysis, and the cathodic current efficiency reached about $50 \%$.

Fig.8 shows the relationship between the cathodic current efficiency and the bath composition in the Ti, Ti-Al and Ti-Fe electrolysis. Clear correlation was seen, and the results seem to be induced to the same relation regardless of the types of deposited metal; the cathodic current efficiency enlarged with the increase in the consumed electric power

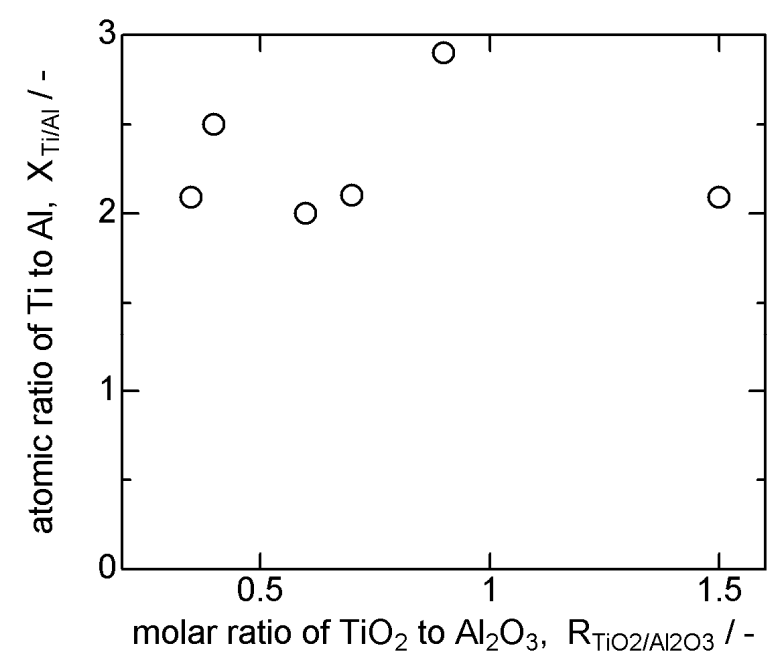

Fig. 6 Dependence of Ti/Al ratio in deposit on $\mathrm{TiO}_{2} / \mathrm{Al}_{2} \mathrm{O}_{3}$ ratio in bath.

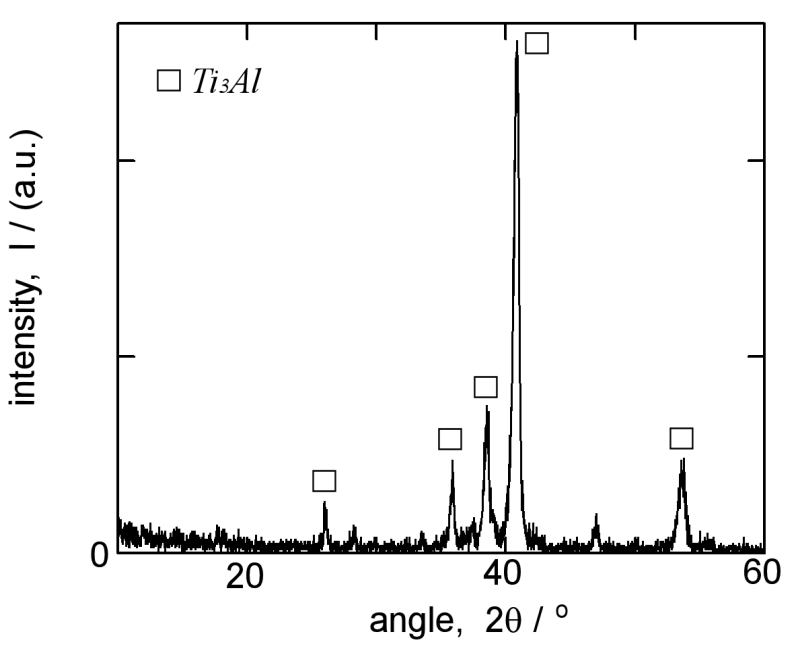

Fig.7 Typical XRD pettern of Ti-Al deposit.

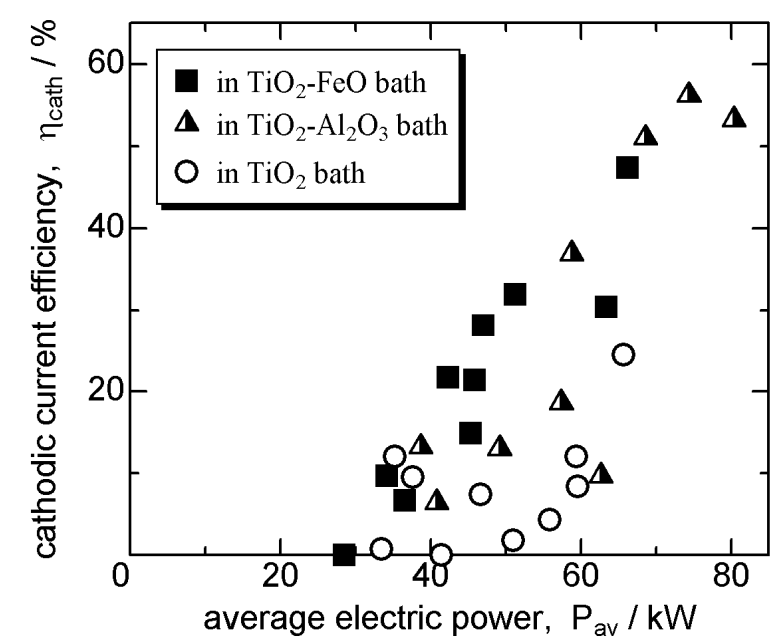

Fig.8 Relationship between average electric power and cathodic current efficiency in Ti, Ti-Al and Ti-Fe electrolysis. 
remarkably. This relation can be explained well by the indirect effect of the bath composition, namely the influence on the metal-pool formation. The cathodic current efficiency in the Ti electrolysis was limited to about $25 \%$ as described in the former section, but Fig. 8 suggests a possibility that the efficiency in the Ti electrolysis can be improved by the electrolysis with lager electric power.

Direct electrodeposition of Ti-Si alloy was also attempted in a $\mathrm{CaF}_{2}-\mathrm{CaO}-\mathrm{TiO}_{2}-\mathrm{SiO}_{2}$ bath. However, the electrolysis was discontinued soon because of pungent smell. Metal deposit has not been obtained in this system yet, though the dependence on the bath composition had not investigated thoroughly.

\section{Prospection of process.}

Although Ti-Si alloy could not be obtained by the process, Ti-Al and Ti-Fe alloys in liquid was produced efficiently. The molar ratio of Ti to $\mathrm{Al}$ in the Ti-Al alloy was $2 \sim 3$ and did not depend on the composition of the slag bath, whereas Ti was co-deposited only in a particular bath composition in the Ti-Fe electrolysis. The difference in the $\mathrm{Ti}$ content in the deposits should be related to the electrochemical properties of $\mathrm{Al}$ and $\mathrm{Fe}$ in comparison with that of Ti. Considering the relationship between the cathodic current efficiency and the consumed electric power, more efficient electrolysis of Ti-Al and Ti-Fe alloy should be possible by optimizing the electrolytic conditions. Direct production of other Ti alloys seems worth trying, too.

The results in this study indicate that lager electric power is required for efficient electrolysis, that is, efficient electrolysis with low consumed energy seems difficult in the process. However, if sufficient temperature to form a metal pool at the cathode is key, desirable electrolysis can be actualized by lower cooling rate of the system. Actually, the system used in this study was rather small, and the flow rate of cooling water was high to keep the system safe enough. Optimizing the cooling of the system should be necessary for better electrolysis.

\section{Summary}

Direct electrolysis of $\mathrm{Ti}$ and some $\mathrm{Ti}$ alloys were attempted by the process using a DC-ESR unit considering the necessary conditions. Liquid $\mathrm{Ti}$ metal was obtained in $\mathrm{a} \mathrm{CaF}_{2}-\mathrm{CaO}-\mathrm{TiO}_{2}$ bath, and a strong influence of the composition of the slag bath on the electrolysis was shown. Electrolysis by using a new type of the electrolytic cell was also carried out to improve the process.

$\mathrm{Ti}-\mathrm{Al}$ alloy was successfully deposited by the process in a $\mathrm{CaF}_{2}-\mathrm{CaO}-\mathrm{TiO}_{2}-\mathrm{Al}_{2} \mathrm{O}_{3}$ bath, whereas Ti-Si alloy has not been obtained in a $\mathrm{CaF}_{2}-\mathrm{CaO}-\mathrm{TiO}_{2}-\mathrm{SiO}_{2}$ bath yet. Ti-Fe alloy was extracted in a $\mathrm{CaF}_{2}-\mathrm{CaO}-\mathrm{TiO}_{2}-\mathrm{FeO}$ bath with high cathodic current efficiency, but the bath composition where significant amount of Ti was contained in the deposit was limited.

A common correlation between the cathodic current efficiency and the average consumed electric power seen in the $\mathrm{Ti}$, Ti-Al and Ti-Fe electrolysis suggested the importance of sufficient temperature in the process. It is expected that more effective electrolysis can be realized by optimizing the cooling of the system.

The works on $\mathrm{Ti}$ and $\mathrm{Ti}-\mathrm{Al}$ electrolysis were supported by the Ministry of Education, Culture, Sports, Science and Technology, Japan(Grand-in-Aid for Scientific Research (A), \#15206084), and that on Ti-Fe electrolysis was supported by ISIJ Research Promotion Grant (2008-2009).

\section{References}

[1] G. Z. Chen, D. J. Fray and T. W. Ferthing, Nature, vol. 407 (2000), p.344.

[2] K. Ono and R. Suzuki, JOM, Feb. (2002), p.59.

[3] K. S. Well, Y. Hovanki and C. A. Lavender, J. Alloys and Compounds, vol. 473 (2009), L39.

[4] C. Francois, International Patent, WO 03/046258, (2003). 
[5] T. Takenaka, T. Suzuki, M. Ishikawa and M. Kawakami;, Electrochemistry, vol. 67 (1999), p. 661.

[6] T. Takenaka, M. Sugawara, H. Matsuo, A. Matsuyama and M. Kawakami, ECS Trans., vol. 16 (2009), p.221.

[7] M. Kawakami, T. Takenaka, T. Kawabata, A. Matsuyama and S. Yokoyama, Proc. Innovations in Titanium Technology Symposium (in TMS2007), (2007), p.145.

[8] A. Matsuyama, T. Kawabata, M. Sugawara, T. Takenaka and M. Kawakami, Proc. 11th World Conference on Titanium (Ti-2007), (2007), p.177.

[9] T.Takenaka, and M. Kawakami, Molten Salts, vol.52 (2009), p.109, in Japanese.

[10] A. J. Bard, ed., Encyclopedia of Electrochemistry of the Element, vol.X, Marcel Dekker, N.Y., (1976). 